\title{
Effectiveness of butterfly-shaped links on structural behavior of slotted steel shear panels
}

\author{
H.M. Ahmadi \& G. De Matteis \\ Department of Architecture and Industrial Design, University of Campania Luigi Vanviteli, Aversa, Italy
}

\begin{abstract}
Steel Plate shear walls (SPSWs) utilize inelasticity properties of the web plate to reinforce and protect the main members of the structures from fatal fracture phenomena against lateral forces. In this study, slotted shear panels with various layouts of butterflyshaped links, which able to control out-of-plane deformations, by concentrating the majority of structural dam-age into the specific internal link elements, are investigated. To evaluate the structural behavior of proposed slotted shear panel, 54 computational models have been considered and analyzed according to previous calibration of the numerical model. The results prove that critical factors of butterfly-shaped links such as slenderness and number of links can improve the seismic performance of the proposed slotted shear panel subjected to shear loads.
\end{abstract}

\section{INTRODUCTION}

Steel Plate Shear Walls (SPSWs) are an efficient dissipative system to be used according to special features to protect high rise buildings against seismic forces (Brando and De Matteis, 2014). The SPSWs are composed by shear panels, boundary elements, plate-frame interactions and beam-to-column connections (Monsef Ahmad et al., 2020). Shear panels often absorb the seismic energy through the tension field mechanism (Monsef Ahmadi et al., 2020). The tension field mechanism is directly dependent on plate-frame interactions and column stiffness (Formisano et al., 2010). Therefore, the connections in the plate-frame interactions are intensively subjected to stress and fracture phenomena (De Matteis et al., 2005). To overcome these disadvantages several methods have been proposed (Formisano et al., 2016). The slotted shear panels represent one of the promising systems. They dissipate lateral forces through yielding mechanism of links between slits. Therefore, the geometry of links has a vital role for ensuring good seismic behavior of such shear panels (Ahmadi and De Matteis, 2020).

Recently, various slotted shear panels have been considered by researchers experimentally and numerically. Ma et al., 2010, investigated slotted shear plates with rectangular and butterfly-shaped links experimentally. The results proved that the number and the slenderness ratios of the links effect the hysteretic response of slotted shear plates. On the other hand, the butterfly-shaped links experienced much more fracture storage than the rectangular shaped links. Along the same line, the taper ratio (i.e., the ratio of end width over the middle width) equal to three had considerable influence on the structural behavior of slotted shear panels. Likewise, Farzampour and Eatherton, 2019, proposed equations to interpret the yielding mechanism of individual butterfly-shaped links through regression analysis. According to the study, the yielding mechanisms of butterfly-shaped links with web plate thickness equal to $(t)$ were highly dependent to taper ratio $(a / b)$, slenderness ratio $(h / t)$ and width ratio $(b / h)$. A geometry of butterfly-shaped link together with the meaning of the above symbols is shown in Figure 1.

DOI: $10.1201 / 9781003132134-49$ 


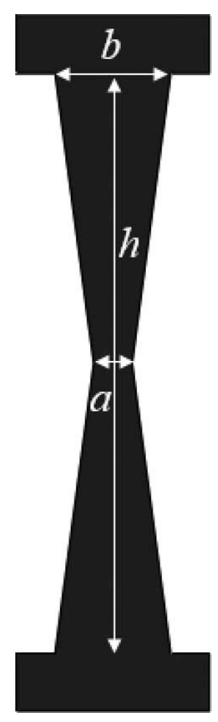

Figure 1. Butterfly-shaped link geometry with thickness $(t)$.

Monsef Ahmadi and De Matteis, 2020, evaluated two different categories of slotted shear panels with butterfly-shaped links by means of numerical analyzes. Each category of specimen was mainly different in relation to the number of butterfly-shaped links. Also, the first and the second categories had various the taper ratios namely three and two, respectively. Therefore, shear strength and initial stiffness of 30 specimens of each category which were different on the web plate and links slenderness ratio were assessed according to nonlinear static analyses (pushover). Furthermore, the hysteretic response of each specimen was estimated. The results illustrated that the shear strength and initial stiffness was decreased by increasing the number of links. On the other hand, the hysteretic response of the first category of specimens was stable especially when the link slenderness ratio was lower than 65 .

In this study, six different categories of slotted shear panels including butterfly-shaped links have been evaluated. Specimens were different in the web slenderness, number, and layout of slits. To gain the main goal of this investigation, a tested specimen was firstly modeled and the corresponding results validated through finite element method by ABAQUS software. Then, the shear strength, initial stiffness, and the effects of the slit pattern of slotted specimens on plate-frame interaction were calculated through nonlinear static analyses.

\section{THE PROPOSED FEM MODEL}

A solid tested specimen, approximately $1 \times 1 \mathrm{~m}^{2}$, with web plate thickness equal to $1.9 \mathrm{~mm}$, was tested under cyclic shear load according to the ATC-24 loading protocol by Egorova et al., 2014. To validate the test results, a finite element model was developed. It consists of shell and beam elements for web plate and boundary members, respectively. The yield strength and the modulus of elasticity of the web plate according to the material properties were $300 \mathrm{MPa}$ and $210 \mathrm{GPa}$, respectively. The narrow mesh size, approximately equal to $15 \mathrm{~mm}$, was calibrated over the web plate. As shown in Figure 2a, there is a good agreement between FE and experimental results in terms of cyclic and pushover analyses. In addition, the FE model has captured correctly the yielding of the web plate in the plate-frame interaction, as shown in Figure $2 b$ by gray color. 
a)

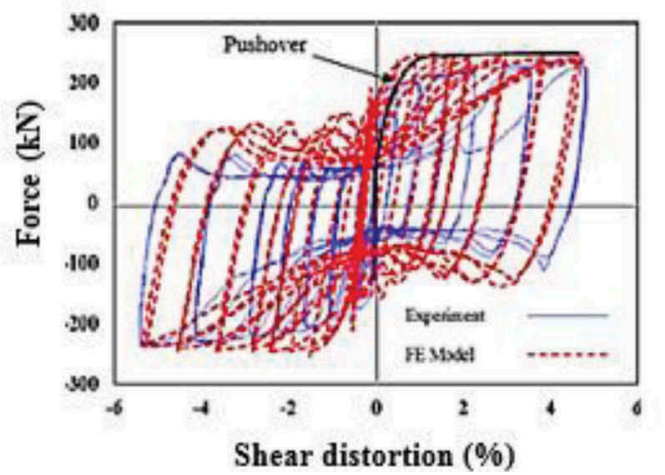

b)

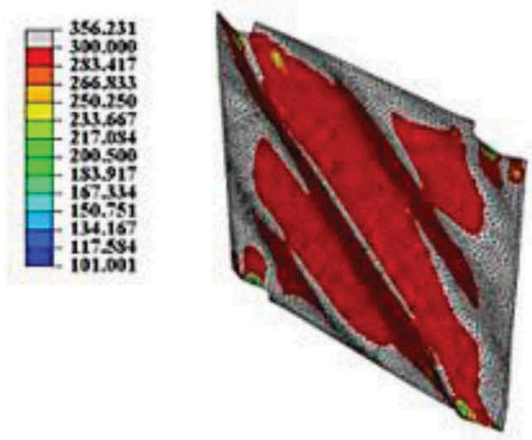

Figure 2. Verification of experimental specimen: a) hysteretic curve and b) von Mises stress (MPa) distribution.

\section{THE ANALYZED SPECIMENS}

To assess the influence of the layout of slits and the web plate slenderness on structural behavior of slotted shear panels, six categories of specimens have been designed as shown in Figure 3. It is worth noticing that the specimens were identical in the taper ratio of links, namely a $=$ $20 \mathrm{~mm}$ and $\mathrm{b}=60 \mathrm{~mm}$. In fact, the considered specimens, as well as the butterfly-shaped links, which varied in their number, (i.e., 18, 10 and 6), had various web plate thickness (i.e., 14, 7 and $3.5 \mathrm{~mm}$ ). Also, different values of $\omega$ (i.e., 80,60 and $40 \mathrm{~mm}$ ), $\alpha$ (i.e., 80 and $140 \mathrm{~mm}$ ) and $\beta$ (i.e., 120 and $180 \mathrm{~mm}$ ) have been considered. Therefore, the considered specimens are named as SP-CA-n-t- $\omega-\alpha-\beta$, in which, $C A$ is category types of slotted layout, $n$ the number of butterfly-shaped links, $t$ is the web plate thickness. The other symbols are considered as shown in Figure 3. For instance, a specimen with name of SP-D-10-14-60-80-120 refers to a specimen of $D$ type category, with ten butterfly-shaped links, web plate thickness equal to $14 \mathrm{~mm}$, having $\omega, \alpha$ and $\beta$ equal to 60,80 and $120 \mathrm{~mm}$, respectively.

a)

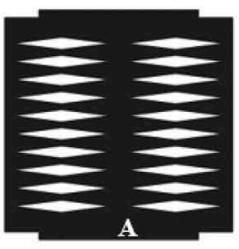

d)

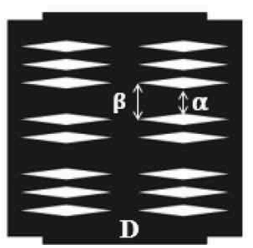

b)

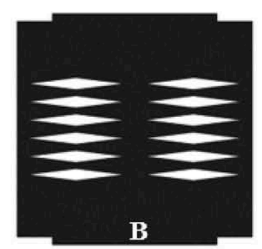

e)

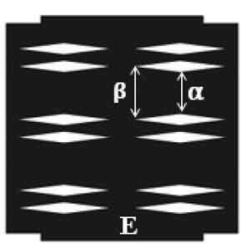

c)

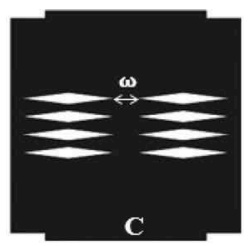

f)

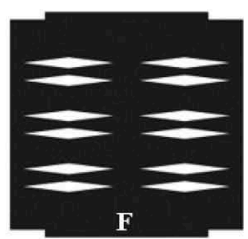

Figure 3. Geometry of considered specimens: a) A, b) B, c) C, d) D, e) E and f) F categories. 


\section{THE OBTAINED NUMERICAL RESULTS}

\subsection{General}

The selected specimens were analyzed according to nonlinear static analyses (pushover) up to $6 \%$ of drift. The bilinear curves were calibrated base on the ECCS method on pushover curves to calculate the yielding point. To this purpose, the shear strength and initial stiffness have been obtained from the numerical results. In addition, the von Misses stress currency of computational specimens at plate-frame interactions to obtain optimum slits layouts have been compared.

\subsection{Shear strength}

The maximum shear strength of computational specimens has been calculated. As shown in Figure $4 \mathrm{a}$, the shear strength of specimens increases when the number of butterfly-shaped links and the web plate slenderness ( $\lambda$ ) (i.e., 62, 123 and 247) decrease. However, the $\omega$ value has minor effect on the maximum shear strength. The shear strength of B and D categories are significantly different from each other. As a result, the layout of slits in the specimens $\mathrm{D}$ produces two butterfly-shaped link with middle and end length of $\alpha$ and $\beta$, respectively. Therefore, the high ratio of the web plate remains in the elastic range in this category of shear panels. Subsequently, this phenomenon occurs also for C, E and F categories. In fact, the specimens type $\mathrm{E}$ category experienced a lower shear strength than $\mathrm{F}$ and $\mathrm{C}$ types.

\subsection{Initial stiffness}

The initial stiffness of investigated slotted shear panels is compared in Figure 4b. It is evidenced that the initial stiffness increases when the number of butterfly-shaped links decreases. On the other hand, the $\omega$ has a slight effect on the initial stiffness. Likewise, the initial stiffness of specimens is not significantly affected by altering the slit layouts.

\subsection{Stress distribution}

To compare the effect of the number and layout of the butterfly-shaped links on distribution of stress at the plate-frame interactions, the von Mises stress related to specimens with web plate slenderness equal to 62 and 247 are shown in Figure 5. It appears that the slotted shear panel by web plate slenderness equal to 247 is prone to develop tension field mechanism due to small web plate thickness. Therefore, the degradation strength happened after $2 \%$ of drift in the specimens.

a)

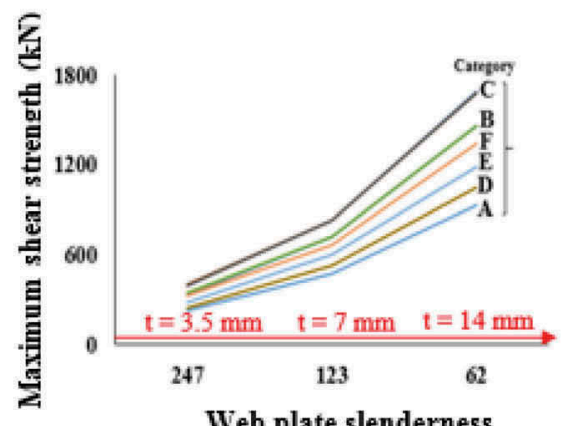

Web plate slenderness b)

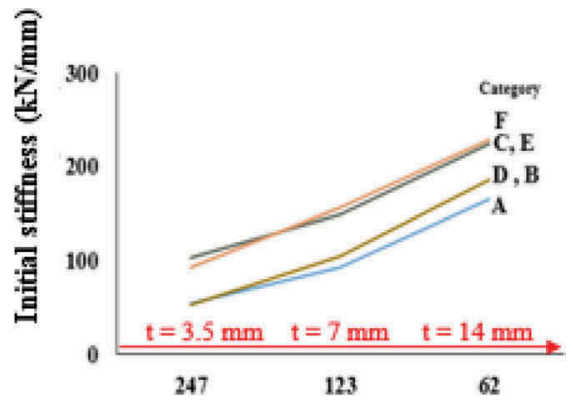

Web plate slenderness

Figure 4. Structural behavior of slotted shear panels versus web plate slenderness in terms of: a) maximum shear strength, and b) initial stiffness. 
a)

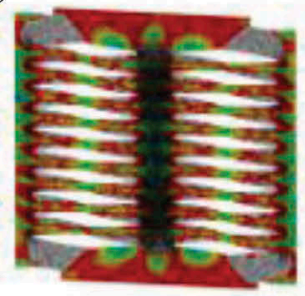

$\lambda=62$

d)

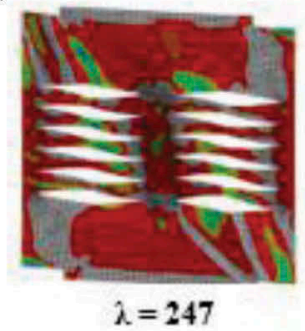

g)

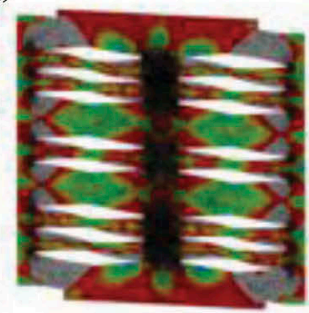

$\lambda=62$

j)

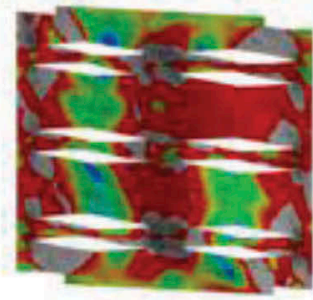

$$
\lambda=247
$$

b)

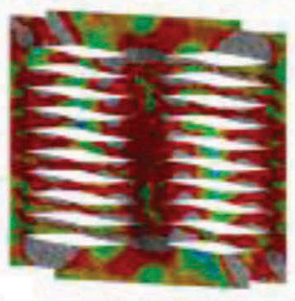

$\lambda=\mathbf{2 4 7}$

e)

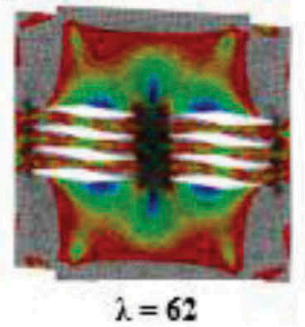

h)

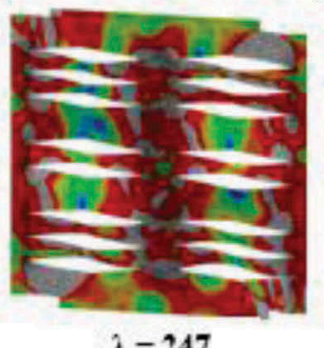

$$
\lambda=\mathbf{2 4 7}
$$

m)

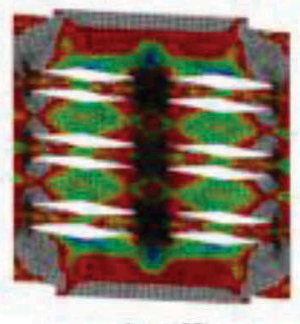

c)

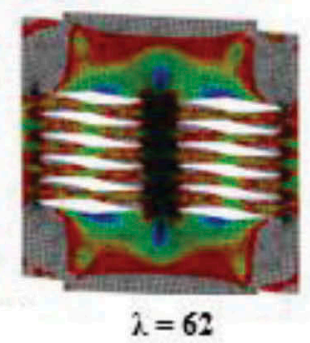

f)

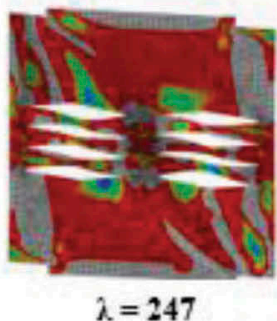

i)

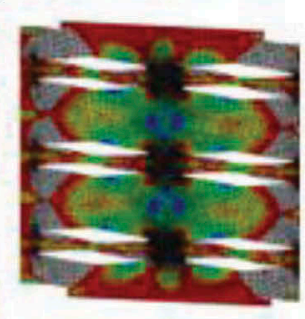

$$
\lambda=62
$$

n)

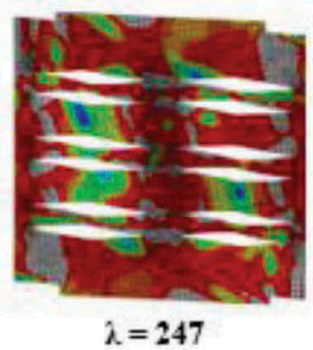

523.5 300.0 275.9 251.8 227.6 203.5 179.4 155.3 131.2 107.0 82.9 58. 8 34.7 10.5

Figure 5. Von Mises stress (MPa) distribution for investigated slotted shear panels.

On the other hand, the stress accuracy of the specimens with web plate slenderness equal to 247 is lower than that of the web plate slenderness equal to 62 in the plate-frame interaction. In the shear panel with web plate slenderness equal to 62 , increasing the number of the butterfly-shaped links, and also the values of theoand $\beta$, has a significant effect to decrease the stress in the plate-frame interaction. This was expected because the shear strength of these types of slotted shear panels is significantly lower when compared to the other ones. Therefore, it is concluded that full slotted shear panels and also high values of $\alpha$ and $\beta$ improve the stress values in plate-frame interaction. 


\section{CONCLUSION}

In this study, the structural behavior of several slotted shear panels including butterfly-shaped links has been investigated numerically. To this purpose, a finite element model which has been calibrated against previous experimental results, has been obtained. Then, various slotted shear panels with different web plate slenderness, slits layout and number of slits have been investigated according to nonlinear static analyses. The results indicated that the maximum shear strength and initial stiffness of slotted shear panels are not dependent on horizontal gaps between links. In addition, it has been ascertained that the maximum shear strength and initial stiffness of slotted shear panels decay when increasing the number of butterfly-shaped links. On the other hand, when decreasing the web plate slenderness, the shear strength and initial stiffness of all types of slotted shear panels increases. The layout of slits has an effect on the distribution of stress in plate-frame interactions. Likewise, such stress decreases when the vertical gaps added between butterfly-shaped links increases. The cyclic behavior of these types of slotted shear panels will be evaluated in terms of maximum equivalent strain and energy-dissipating capacity by further investigations.

\section{ACKNOWLEDGEMENTS}

This research work has been developed as part of a $\mathrm{PhD}$ project, within the framework of the VALERE program (Vanvitelli per la Ricerca) of the University of Campania” Luigi Vanvitelli”.

\section{REFERENCES}

Ahmadi HM and De Matteis G (2020) Seismic performance of steel shear panels with butterfly- shaped links. International Journal of Earthquake engineering 37 (1)85-101.

Brando G and De Matteis G (2014) Design of low strength-high hardening metal multi-stiffened shear plates. Engineering Structures 60. Elsevier: 2-10.

De Matteis G, Formisano A, Mazzolani FM, et al. (2005) Design of low-yield metal shear panels for energy dissipation. In: Improvement of Buildings' Structural Quality by New Technologies. CRC Press, pp. $677-688$.

ECCS (1985) Recommended Testing Procedures for Assessing the Behaviour of Structural Elements under Cyclic Loads.

Egorova N, Eatherton MR and Maurya A (2014) Experimental study of ring-shaped steel plate shear walls. Journal of Constructional Steel Research 103. Elsevier: 179-189.

Farzampour A and Eatherton MR (2019) Yielding and lateral torsional buckling limit states for butterfly-shaped shear links. Engineering Structures 180. Elsevier: 442-451.

Ma X, Borchers E, Pena A, et al. (2010) Design and behavior of steel shear plates with openings as energy-dissipating fuses. John A. Blume Earthquake Engineering Center Technical Report, (173).

Formisano A, De Matteis G and Mazzolani FM (2010) Numerical and experimental behaviour of a full-scale RC structure upgraded with steel and aluminium shear panels. Computers \& structures 88 (23-24).Elsevier: 1348-1360.

Formisano A, Lombardi L and Mazzolani FM (2016) Perforated metal shear panels as bracing devices of seismic-resistant structures. Journal of Constructional Steel Research 126. Elsevier: 37-49.

Monsef Ahmad H, Sheidaii MR, Tariverdilo S, et al. (2020) Experimental and Numerical Study of Perforated Steel Plate Shear Panels. International Journal of Engineering 33 (4). Materials and Energy Research Center: 520-529.

Monsef Ahmadi H, Sheidaii MR, Boudaghi H, et al. (2020) Experimental and numerical study on largely perforated steel shear plates with rectangular tube-shaped links. Advances in Structural Engineering. SAGE Publications Sage UK: London, England: 1369433220937147.

Simulia DS, Fallis A and Techniques D (2018) Abaqus 6.14 Online Documentation.Abaqus Web. 